\title{
The Times-Picayune y los discursos noticiosos sobre el colapso del periodismo norteamericano
}

\author{
María LUENGO CRUZ \\ Universidad Carlos III de Madrid \\ maria.luengo@uc3m.es
}

Recibido: 01/10/2012

Aceptado: 08/04/2013

\begin{abstract}
Resumen
El 1 de octubre de 2012 la ciudad de Nueva Orleans (Luisiana) se convirtió en la primera ciudad más grande de Estados Unidos sin un periódico diario. Meses antes, los dueños del periódico decidieron reducir a tres días la edición impresa de The Times-Picayune. Este artículo analiza el modo en el los discursos periodísticos sobre los cambios en este diario, la revolución digital y el colapso económico de la prensa construyeron la denominada crisis del periodismo norteamericano. Los periodistas asumen un conjunto de códigos culturales que sitúan los hechos dentro de las fronteras simbólicas de lo profesionalmente se entiende como buen periodismo o, por el contrario, fuera de estos límites. Estos supuestos culturales explican el conflicto profesional entre el periodismo tradicional y los nuevos desafíos que plantea Internet; un debate polémico motivado, en gran medida, por el tipo de valores hacia los cuales ha tendido la profesionalización del periodismo norteamericano.

Palabras clave: crisis del periodismo; revolución digital; sociología cultural; diario impreso; Times-Picayune

\section{The Times-Picayune and the News Discourses on the Collapse of American Journalism}

\begin{abstract}
This article analyses the ways in which the crisis of American journalism is constructed in the journalistic discourses on the digital revolution and the economic collapse of newspaper through the particular case of The Times-Picayune. Journalists assume a set of cultural codes which locates the facts within symbolical boundaries of what is professionally understood as good journalism or, on the contrary, outside these boundaries. These cultural assumptions might account for the professional conflict between the traditional journalism and the new challenges posed by the Internet; a crisis greatly motivated by the kind of values towards which the professionalization of American journalism has tended.
\end{abstract}

Keywords: crisis of journalism; digital revolution; cultural sociology; print journal; Times-Picayune

\section{Referencia normalizada}

LUENGO CRUZ, María (2013): "The Times-Picayune y los discursos noticiosos sobre el colapso del periodismo norteamericano". Estudios sobre el Mensaje Periodístico. Vol. 19, Núm. 2 (julio-diciembre), págs.: 733-749. Madrid, Servicio de Publicaciones de la Universidad Complutense.

Sumario: 1. Introducción. 2. Marco teórico: el periodismo como ritual y práctica cultural. 3. El caso de The Times-Picayune : muestra y análisis; 3.1. La construcción del discurso noticioso: la revolución digital y el colapso económico del periodismo; 3.2. Periodismo de calidad versus 24 horas de noticias online; 3.3. Comunidad versus individuo. 4. Conclusiones. 5. Referencias.

\section{Introducción}

"Un periódico, incluso falto de publicidad, es un excelente anuncio de, al menos, una cosa: el periódico en sí mismo. La constancia de un periódico diario -en el estante de la tienda de ultramarinos en la calle Frenchman o en las mesas de la cafetería en la calle Maplesirve a una ciudad de recordatorio de que hay alguien vigilando ahí fuera. Todavía queda 
por hacer un periodismo importante en The Times-Picayune de Nueva Orleans. [...]. Pero cabe preguntarse si tendrá el mismo impacto cuando no llegue, día tras día, a las puertas de toda la ciudad".

David CARR, "Un trágico romance con un periódico", The New York Times, 28 de mayo de 2012

El 23 de mayo de 2012 David Carr, periodista de The New York Times, fue el primero en dar la noticia que ha vuelto a reavivar el debate sobre la crisis y el futuro del periodismo norteamericano (Edmonds, 2012; Myers, 2012; Stearns, 2012; Carr, 2012): Nueva Orleans podría convertirse en la ciudad más grande de los Estados Unidos sin un periódico diario a finales de este mes de septiembre de 2012. Según el artículo de Carr (2012), The Times-Picayune, uno de los diarios más antiguos en Estados Unidos, galardonado con dos premios Pulitzer por la cobertura del huracán Katrina y diario de referencia en la ciudad de Nueva Orleans, dejaría de publicarse en papel los siete días de la semana, pasando a solo tres. Al día siguiente, Advance Publications, la empresa editora del diario y propiedad de la familia Newhouse, respondió a la noticia en un artículo publicado en la página web del periódico. La compañía confirmó la constitución de una nueva empresa, NOLA Media Group, que incluiría el periódico y su página web, nola.com. Con ello, Advance Publications pretendía fortalecer el sitio web que pasaría a convertirse en una plataforma de noticias online las 24 horas del día durante toda la semana, mientras que la edición en papel quedaría reducida a tres días de la semana, miércoles, viernes y domingos.

Los cambios en The Times-Picayune parecían responder a la estrategia de recortes de ediciones impresas y la orientación del negocio hacia nuevas plataformas digitales que Advance Publications ha llevado a cabo con otros de sus diarios locales en Misisipi y Míchigan. Tras confirmar la noticia sobre The Times-Picayune, el grupo anunció medidas similares en sus tres cabeceras locales de Alabama: The Birmingham News, Press-Register of Mobile y The Huntsville Times.

En las noticias sobre The Times-Picayune los periodistas identificaron los hechos como manifestación del colapso económico y la revolución digital que afectan al periodismo norteamericano. The Times-Picayune añadía un nuevo caso al número de diarios en el país que han sufrido severamente la reducción de costes y de personal, e incluso han desaparecido por completo como consecuencia de operaciones de centralización y fusión de redacciones impresas y digitales. Sin embargo, los discursos periodísticos presentaron a este diario como expresión singular de la crisis. Un artículo publicado el 25 de mayo de 2012 en The New York Times abrió el relato con estas palabras: "[...] un símbolo de la resistencia valiente de la ciudad durante el huracán Katrina y sus secuelas, ha cedido a las presiones del mercado de la prensa moderna". No se trata de un periódico más que sucumbe a la situación del mercado, sino de la prestigiosa cabecera de Nueva Orleans, una de las más antiguas del país. Desde hace 175 años, el periódico no ha dejado de publicarse a diario, salvo los tres famosos días entre agosto y septiembre de 2005 en los que el periódico no pudo salir a la calle debido a que la redacción quedó inundada por el paso del huracán Katrina. Pese a todo, un grupo de periodistas decidió permanecer en Nueva Orleans para informar de la ca- 
tástrofe a través de la página web. Nola.com se convirtió en soporte de un periodismo ciudadano que facilitó la búsqueda de personas desaparecidas. Por la cobertura de la catástrofe, el periódico ganó dos premios Pulitzer.

Por lo demás, la singularidad del caso se confirmó poco después con movilizaciones ciudadanas, paradójicamente, a través de las redes sociales -la cuenta en Facebook "SaveThePicayune" cuenta con unos 3.850 seguidores-, manifestaciones y campañas a favor del periódico, y un manifiesto firmado por el denominado Grupo de Ciudadanos de TheTimes-Picayune con representantes locales del mundo de la política, el arte o los negocios, entre otras iniciativas.

La crisis del periodismo americano tiene, sin duda, su paralelo en España y en otros países europeos. En Estados Unidos, el fenómeno ha sido descrito mediante términos cada vez más dramáticos. Por ejemplo, se habla de "colapso" del periodismo, palabra que figura en una de las últimas compilaciones de artículos firmados por académicos y profesionales en Estados Unidos (McChesney \& Pickard, 2011). Este libro completa y mantiene actualizada la amplia lista de aportaciones profesionales y académicas que, desde 2008, tratan de ofrecer razones y respuestas a la crisis del periodismo, y, hasta el momento, su buque insignia, el diario impreso (véase, por ejemplo, Fuller, 2010; Jones, 2009; Alterman, 2011; VV.AA, 2009). En España, estos estudios coinciden, por lo general, en ofrecer explicaciones tecno-económicas y, como consecuencia, soluciones encaminadas a la implantación de nuevos negocios empresariales orientados hacia Internet (Pérez-Latre y Sánchez-Tabernero, 2012; Farias y Roses, 2009; Larrañaga, 2009).

Los cambios tecnológicos, económicos y demográficos son, sin duda, reales y están conmocionando a la profesión. Sin embargo, según advierte Alexander (2011: 3), "[los factores materiales y sociales] no hablan por sí mismos". Cuando los hechos entran en el debate social, "lo hacen como signos que incorporan estas realidades empíricas a estructuras ya existentes de símbolos". A base de insistir en las transformaciones materiales, podría parecer que la denominada crisis del periodismo es el resultado directo de las estructuras económicas y de las innovaciones tecnológicas, como si las prácticas profesionales estuviesen determinadas mecánicamente por dichos cambios materiales.

Sin obviar los nuevos contextos socio-económicos y tecnológicos que afectan hoy al periodismo, esta investigación pone el acento en los factores culturales. El estudio pretende mostrar el modo concreto en el que la crisis del periodismo es construida por los propios periodistas, en particular, a través del relato, la interpretación y valoración de los acontecimientos sobre The Times-Picayune. El estudio observa cómo los periodistas emplean un conjunto de códigos culturales que sitúan a protagonistas, acciones, motivaciones, circunstancias y consecuencias de los hechos dentro de los márgenes simbólicos de lo que profesionalmente se considera como buen periodismo en Estados Unidos o, por el contrario, fuera de estos márgenes. La asunción de estos códigos explicaría buena parte de las tensiones generadas entre la defensa del periodismo convencional y los retos que plantea la Red. A su vez, esta explicación permitiría dimensionar mejor la crisis del periodismo; una crisis motivada en gran parte por el tipo de valores hacia los cuales ha tendido la profesionalización del periodismo en Estados Unidos. 
En lo que sigue, la primera parte del artículo plantea las claves teóricas que justifican el enfoque cultural adoptado. La segunda parte contiene el estudio de caso: un análisis de los textos periodísticos publicados con motivo de los recortes en la impresión diaria de The Times-Picayune, la oposición de los ciudadanos de Nueva Orleans y el despido de periodistas ocasionado por la reconversión del periódico. Los apartados que componen esta sección detallan la metodología y presentan los resultados y conclusiones más relevantes.

\section{Marco teórico: el periodismo como ritual y práctica cultural}

Según James Carey (1989: 18), definir el periodismo desde un punto de vista cultural implica clarificar su significado en términos de "participación", "asociación" o "posesión de una fe común". "Esta definición -afirma Carey- utiliza el significado antiguo de (comparte raíces comunes con) los vocablos "comunión", "comunidad" y "comunicación". Una visión ritual de la comunicación no se dirige a la extensión de mensajes en el espacio, sino al mantenimiento de la sociedad en el tiempo; no al acto de transmitir información, sino a la representación de creencias compartidas". Este carácter ritual del periodismo, que resalta el poder de las noticias para cohesionar a una sociedad (Dayan and Katz, 1992), también permite esclarecer la clase de vínculo que sustenta a la propia comunidad de periodistas (Carlson, 2012).

En los últimos años, estudiosos del periodismo han evidenciado la existencia de una ideología profesional a través de la cual los periodistas crean y consolidan su identidad colectiva (Schudson, 2001; Zelizer, 2004; Deuze, 2005; Patterson y Donsbach, 1996). Dicha ideología se compone de un conjunto de valores típico-ideales como la independencia, la neutralidad o la objetividad que varían según el contexto socio-cultural, temporal y geográfico (Deuze, 2005). Por ejemplo, Schudson $(1978,2001)$ ha documentado el origen de la norma de la "objetividad" en periodismo norteamericano. El autor advierte que la búsqueda del prestigio de la ciencia, la eficacia y el progreso influyeron en la generación de esta norma que, en torno a 1920, adquirió su plena formulación como ideal profesional, como "parte de un proyecto o misión" (Schudson, 2001: 163). De este modo, la objetividad prevaleció en la práctica del periodismo norteamericano a lo largo del siglo $\mathrm{XX}$, a modo de criterio conformador de la ideología profesional en Estados Unidos.

Desde un punto de vista pragmático, los periodistas conciben esta objetividad y otro tipo de códigos morales como forma de salvaguardar su reputación, justificar su actividad o defenderse de las críticas, e incluso de las demandas judiciales, que podría ocasionar su labor (Schudson, 2001; Soffer, 2009; Deuze, 2005; Patterson y Donsbach, 1996; Statham, 2008). Pero también es cierto que existe un compromiso auténtico por parte de los periodistas con muchos de estos códigos y creencias que identifican a la profesión. Así lo demuestra empíricamente Revers (2012) en un trabajo reciente sobre el modo en el que los periodistas hablan de criterios morales para defender su autonomía profesional respecto a sus fuentes personales de información. Mediante un análisis etnográfico de las respuestas dadas por un grupo representativo de periodistas de información política en Albany, Nueva York, el autor prueba que, en efecto, los periodistas son muy sensibles a las acusaciones de violación de principios 
profesionales. No obstante, las respuestas trascienden este nivel de la autoestima profesional. El análisis de Revers revela que la adhesión a estándares profesionales -por ejemplo, una actitud crítica respecto a las fuentes políticas- refuerza la autonomía periodística, facilita el flujo comunicativo con las fuentes e impulsa la propia cobertura informativa del evento en cuestión -una actitud crítica puede afectar a cómo los acontecimientos son percibidos por otros periodistas y por el público en general, y todo ello en la respuesta de las propias fuentes políticas que suministran la información-. En palabras de Bourdieu, Revers mantiene que el "nomos" periodístico -el conjunto de leyes internas que constituye la lógica de la práctica profesional- no se basta a sí mismo. La definición de dichas normas responde, en efecto, a la demarcación, diferenciación y defensa del "campo" periodístico frente a otros campos. Pero ese conjunto de normas morales remite, a su vez, a fronteras simbólicas que vinculan la práctica profesional a conductas y valores cívicos presentes en la sociedad americana.

Otros autores han advertido este vínculo cultural entre las prácticas y los discursos periodísticos y los códigos morales de la sociedad civil (Breeze, 2011; Alexander, 2006; Alexander y Jacobs, 1998; Jacobs, 2000; Jacobs, 2009). Breeze (2011) formula dicha relación a través de una estructura binaria de códigos opuestos -imparcial versus partidista; informativo versus entretenido; equilibrado versus sesgado; preciso versus distorsionado; mesurado versus sensacionalista; etc.-. Su propuesta destaca una serie de ideales, valores y cualidades del buen periodismo que adquieren sentido en relación a sus opuestos. Los atributos positivos se sitúan en el lado de la sociedad civil. En el lado contrario, los atributos negativos conforman el entorno simbólico de lo anti-cívico'. Según Breeze (2011), el ejercicio de la profesión en Estados Unidos se ha organizado culturalmente en torno a este esquema binario de códigos cívicos y anti-cívicos. La autora prueba que este esquema estructuró los discursos periodísticos sobre la profesión en torno a 1980, a su juicio, un momento álgido en el periodismo norteamericano, lleno de informaciones y opiniones sobre las propias noticias y, en particular, la información televisiva. Dos acontecimientos motivaron el debate: Dan Rather reemplazó a Walter Cronkite, el veterano presentador del programa de la CBS, Evening News, y Ted Turner lanzó el primer canal de 24 horas de noticias en Estados Unidos. En el estudio de este último caso, la autora avanza la tesis que confirmaremos más adelante mediante el caso de The Times-Picayune, la reducción de la edición impresa a favor de la página web: Cable New Network $(\mathrm{CNN})$ y lo que este nuevo canal significaba -mayor cantidad de informaciones emitidas en tiempo real- fue codificado en términos de valores y contravalores cívicos. Por un lado, mayor exposición infor-

1 En la línea de Claude Lévi-Strauss, Mary Douglas y, más directamente, Jeffrey C. Alexander (2006), Breeze fundamenta su propuesta en la idea de que actores e instituciones sociales, también los medios de comunicación, se estructuran simbólicamente en categorías binarias de lo puro e impuro. Siguiendo a Alexander, la autora relaciona lo puro con los ideales de la sociedad civil y lo impuro, con contravalores fuera de la esfera civil. Así, por ejemplo, motivos, actores e instituciones que trabajan a favor de una sociedad abierta, democrática, tolerante, etc., se contraponen a aquellos que son calificados de cerrados, elitistas o intolerantes. 
mativa implicaba más tiempo para desarrollar las noticias y, consecuentemente, un tratamiento más amplio y profundo de la información. Todo lo contrario a la superficialidad con la que podían ser tratadas las informaciones en el escaso tiempo otorgado a las programas de noticias en las cadenas convencionales. Por otro lado, la cantidad conllevaba falta de seriedad y rigor, espectacularidad y especulación.

Bajo el marco de estos códigos culturales compartidos en la profesión, se trataría entonces de dirigir el análisis hacia el tipo de valores que, en concreto, los periodistas emplean para discutir sobre la naturaleza del periodismo con motivo de los cambios particulares en la industria de la prensa y la conversión hacia la tecnología digital. ¿De qué modo estos significados colectivos entran en momentos clave del debate público sobre la crisis del periodismo? ¿Hasta qué punto construyen el propio discurso del colapso del periodismo? ¿Estamos ante un conjunto reducido de normas que limitan los esfuerzos de autocrítica de los propios periodistas, tal y como argumenta Carlson (2012) en el caso particular de los discursos periodísticos a propósito del fallecimiento en 2009 de Walter Cronkite, el venerado presentador de la CBS? ¿O, por el contrario, se trata de valores que custodian vínculos genuinos de la actividad periodística con el bien común de la sociedad civil? ¿En qué medida permiten la apertura hacia nuevas concepciones de la profesión? De entrada, la perspectiva cultural conceptualiza el periodismo como representación y al periodista como actor que interpreta la realidad desde un guión de significados compartidos por la sociedad. Esto contrasta con la idea de transmisión de mensajes que, de acuerdo con Carlson (2012), estaría detrás de concepciones más normativas de la profesión (la norma de la objetividad). El análisis cultural abriría una vía diferente para sostener otro tipo de cualidades que legitiman la autoridad del periodismo. Esta vía es explorada por Carlson en el estudio anteriormente citado sobre las reacciones de periodistas a la muerte Cronkite. Frente a los valores normalmente acuñados de la objetividad, la distancia o el desinterés, los periodistas explican el éxito y la autoridad de Cronkite por su cercanía con el público y otros criterios que se desligan del tradicional estándar de la objetividad periodística.

\section{El caso de The Times-Picayune : muestra y análisis}

El principal diario de Nueva Orleans, The T-P, tal y como es denominado familiarmente por sus siglas, representa la tradición y el buen hacer del periodismo norteamericano. El periódico celebró su 175 aniversario este año. Fundado en 1837 bajo los principios de la nueva prensa económica -el periódico valía seis céntimos frente a los diez que costaban los periódicos competidores-, la inicial cabecera, The Daily Picayune, sobrevivió a los primeros pasos del nuevo periodismo en los Estados Unidos de la segunda mitad del siglo XIX. Entonces nuevos periódicos proliferaban sostenidos por pequeños capitales, pero a duras se mantenían en el mercado, al tiempo que la novedad por la prensa de actualidad y la pasión por la noticia convivía con la prensa de opinión (Weill, 1941). A principios del siglo XX, el periódico fue perfilando un carácter fuerte, crítico y luchador por el buen gobierno de Nueva Orleans. Consiguió valerse la independencia del poder político en momentos difíciles. Escritores de prestigio como William Faulkner y William Sidney Porter trabajaron para The Times-Pi- 
cayune. En la década de los noventa, el diario se convirtió en uno de los diarios más importantes del país. Jim Amoss recibió el título de Editor del Año por la National Press Foundation en 1997. Este mismo año el periódico obtuvo dos premios Pulitzer. Uno de ellos reconocía el servicio público. Esta labor de servicio al ciudadano fue premiada de nuevo en 2005 con dos Pulitzer por la cobertura del huracán Katrina.

El estudio analiza los discursos periodísticos sobre el recorte de la edición impresa de The Times-Picayune, la oposición por parte de los ciudadanos de Nueva Orleans y el despido de periodistas. El periodo de estudio abarca dos meses, desde el 23 de mayo de 2012, día en el que The New York Times publica la noticia de los cambios en el periódico, hasta el 23 de julio de 2012, momento en el que ya se han cubierto los hechos que siguen a las primeras medidas de recortes: la reacción de los ciudadanos y el despido de periodistas. Una búsqueda del término "Times-Picayune" durante el periodo indicado a través de la base de datos Factiva generó un total de 102 textos procedentes de medios de comunicación norteamericanos. La muestra se completó con 26 contribuciones de periodistas en blogs. En total 128 textos únicos fueron analizados temáticamente mediante técnicas de codificación abierta y axial². Para esta segunda fase de codificación axial, se empleó un paradigma narrativo cuyos componentes básicos organizaron los datos procedentes de la codificación abierta en forma de acciones, actores, motivos, consecuencias y circunstancias espacio-temporales. En el proceso de codificación, se distinguió entre el relato de los hechos contenido en artículos de carácter noticioso y las observaciones, interpretaciones y valoraciones incluidas en blogs y artículos de opinión. La diferenciación de textos por el tipo de artículo -informativo, interpretativo o de opinión- facilitó, por un lado, el examen de la reconstrucción periodística de los hechos y, por otro, el estudio de la valoración de los acontecimientos por parte de los periodistas. Por último, se tuvo en cuenta de qué medio procedía cada artículo. Fundamentalmente, se analizaron aparte los textos publicados por The Times-Picayune y su página web, Nola.com, pues en principio reflejaban el punto de vista de los editores o de periodistas afectados por las medidas de los recortes y despidos.

\subsection{La construcción del discurso noticioso: la revolución digital y el colapso eco- nómico del periodismo}

La mayoría de los artículos refieren los hechos en torno a The Times-Picayune a la denominada "la revolución digital" que ha estado y sigue estando en el centro del debate sobre la crisis y el futuro de la profesión en Estados Unidos. En el campo del periodismo, esta expresión condensa todos aquellos cambios que Internet introduce en la producción y el consumo de noticias. La web del diario, Nola.com, deja claro este argumento tecnológico cuando publica la notificación de los cambios en The Times-Picayune. El artículo informa de la apuesta de Advance Publications por la plataforma

${ }^{2}$ La codificación abierta secciona el texto y lo cifra en conceptos, categorías y sub-categorías con sus correspondientes propiedades y dimensiones. Por su parte, la codificación axial ensambla de nuevo el documento relacionando categorías y sub-categorías (Crobin y Strauss, 2008). 
digital. La noticia enfatiza la idea de novedad y reforzamiento de la cobertura de noticias online las 24 horas del día. El desafío de la tecnología digital supondrá sacrificios en el periódico impreso, que se publicará sólo tres días por semana. Ricky Mathews, presidente de la nueva compañía, asegura que muchos de los periodistas contratados en The Times-Picayune tendrán la oportunidad de crecer profesionalmente dentro de la nueva organización. Mathews lamenta, sin embargo, la inevitable reducción de planti1la, que se llevará a cabo con el objetivo de acelerar el crecimiento digital. Noticias procedentes de otros medios también se hacen eco los argumentos de Mathews y otros directivos de Advance Publications a favor del cambio hacia lo digital. Sin embargo, luego veremos que el argumento de las 24 horas también es codificado de manera muy distinta a como lo hacen los empresarios de Advance Publications, esta vez fuera de la esfera de los valores cívicos y los estándares profesionales.

El discurso de la revolución digital aparece estrechamente ligado al del "colapso económico" del negocio periodístico en el país, sobre todo del diario impreso. Los diarios han experimentado una caída drástica de ingresos por ventas y publicidad: los lectores optan por la Red para informarse de manera gratuita, y los anunciantes siguen a los lectores a través de este medio para dar a conocer sus productos. The Wall Street Journal (24 de mayo de 2012) recoge y analiza estas otras razones económicas que motivaron los recortes de acuerdo con directivos de Advance: "[Mr. Newhouse, dueño de Advanced Publications] dice que la decisión de reducir la edición impresa en Nueva Orleans fue 'un resultado de las condiciones del mercado"'. Los cambios son síntoma de un gran malestar en la industria de los periódicos. Este artículo de The Wall Street Journal presenta una relación de otros diarios que han pasado por la misma situación, han sufrido reducciones en sus versiones impresas o incluso han desaparecido. En un artículo de The New York Post (30 de mayo de 2012), Keith J. Kelly traslada la inquietud y el temor dentro de las redacciones hacia la cadena de reducciones en la impresión diaria de periódicos pertenecientes a Advance Publications. El descenso de ingresos por publicidad podría ocasionar recortes en otras cabeceras diarias del grupo.

Si bien estas razones técnicas y económicas articulan las principales categorías del discurso noticioso, los cambios materiales no son percibidos por igual en los distintos medios de comunicación. Estos matices de percepción resultan importantísimos en la medida en que determinan la propia construcción de las noticias. El tono discursivo tiene que ver con el modo en el que las aludidas categorías de "revolución digital" o "colapso económico", a las que se adscriben los hechos, se relacionan con otros conceptos o sub-categorías asociadas -"24 horas de noticias" o "páginas Web de noticias", "información digital", "noticias impresas"-. A su vez, estas conexiones entre categorías arrojan luz sobre los principios meta-discursivos a partir de los cuales los propios periodistas codifican los hechos.

\subsection{Periodismo de calidad versus 24 horas de noticias online}

A excepción de los artículos publicados en Nola.com, los textos contraponen, por lo general, la reducción de la edición impresa de The Times-Picayune, ejemplo de calidad periodística, a la ampliación de noticias online las 24 horas del día. En un repor- 
taje para The New York Times, "La ruina del diario" (4 de junio de 2012), Christine Haughney plantea las posibles consecuencias para The T-P aludiendo a las repercusiones que ha tenido la desaparición, en 2009, de otro diario de Advance Publication, The Ann Arbor News, a favor del sitio web: "Los cambios más notables han afectado al contenido [...] Mientras el sitio web AnnArbor.com ha mejorado, la web y el periódico en papel pierden columnas de opinión, artículos y piezas de investigación". Haughney recoge también la opinión de Geoff Larcom, periodista veterano del diario impreso quien, tras haber asistido al cierre del diario y a su sustitución por el sitio web, AnnArbol.com, renunció a un nuevo trabajo en la página web: "El punto-com es una entidad que funciona mucho más a golpe de noticias. [...]. No te haces una idea general de la ciudad".

Otro de los entrevistados por Haughney, Charles R. Eisendrath, director de Knight Wallance Journalism Fellows de la Universidad de Míchigan, habla de la poca fiabilidad que personalmente le inspira el sitio web: "¿Se discute de AnnArbol.com en Ann Arbol? No. ¿Es una autoridad? No. No me fío de nada que se haga a bajo precio". Margaret Sullivan, en The Buffalo News (25 de mayo de 2012), resume varias de las razones expuestas por Warren Buffett, uno de los mayores inversores de la compañía dueña del periódico, a favor del éxito y la permanencia de los diarios impresos de su empresa, a diferencia de la suerte que han corrido los periódicos de Advance Publications. Entre otros motivos, Sullivan contempla la prioridad dada a los asuntos serios, políticos, de interés público. En su artículo "How to worry about a clicks-driven TimesPicayune" (Columbia Journalism review, 20 de Julio de 2012), Sarah Carr enumera las noticias más visitas de Nola.com en el mes de junio para mostrar que "en un escenario apocalíptico, leeríamos solo sobre sexo, deportes, crimen y más crimen”. [...] Las 100 historias más populares del mes no incluyen la cobertura de educación, salud, inmigración o vivienda. Menos de diez por ciento de las historias se refirieron únicamente tangencialmente a asuntos públicos y política".

El reforzamiento de sitios web de noticias se relaciona, pues, con la cobertura online las 24 horas del día, y ambos fenómenos son codificados como opuestos a un periodismo de calidad. Chris Rose, un famoso periodista de The Times-Picayune que dejó el periódico en 2009, relata así su experiencia en el diario cuando, en sus términos "la preocupación por la página web ya estaba en pleno auge" y "blogging era el mantra diario" (Oxford America, 27 de agosto de 2012):

"[Ya entonces] estábamos alimentando a una bestia insaciable. Sentía como nunca que la mitad de mi salida no era tanto del periódico en papel como del sitio web.

Como muchos otros de mi posición y temperamento -viejos cabezotas, supongo- la cobertura informativa en la Red es anatema de todo aquello que me gusta de periodismo: conseguir un dato, tirar del cable, dar cuerpo a los detalles y, entonces, contar la historia. Ahora todo se detiene en el dato. Solo tienes que verificarlo (¡ojalá!) y publicarlo. No volví a escribir historias nunca más. Producía contenido".

Frente a la profundidad, el rigor, la selección y la seriedad del diario impreso, las páginas web de noticias conllevan superficialidad, imprecisión, mezcla y ligereza. En "Media Decoder", el blog sobre medios de comunicación de The New York Times, Noam Cohen (NYT Blogs, 25 de mayo de 2012) destaca y contrasta estas dos noticias 
en el titular: "Nueva Orleans, sin periódico diario, y China invierte en películas". Cohen vincula el déficit de información en la comunidad Nueva Orleans con el superávit de entretenimiento global. A la decisión de recortar la impresión del periódico, a favor de la plataforma de 24 horas de noticias online, le sigue el anuncio de compra de AMC Entertainment, la segunda cadena de cines más grande en Estados Unidos, por el grupo Wanda, del magnate chino Wang Jianlin, con intereses cercanos al gobierno de Beijing, y aspiraciones de crear una marca de entretenimiento de alcance global.

Empresarios y medidas que impulsan el cambio en The Times-Picayune son simbólicamente posicionados en este último lado de valores antagónicos: "Quieren que [los periodistas] produzcan más entradas de blog por día, y ni siquiera se preocupan de poner las cosas juntas en un paquete más reflexivo", afirma Brian Thevenot, director de negocios de St. Louis Post-Dispach, en el reportaje anteriormente citado de The New York Times (4 de junio 6 de 2011). En la exclusiva que David Carr publica en The New York Times (23 de mayo de 2012), el periodista menciona el silencio de los directivos ante los requerimientos de información. Frente a la negativa a declarar, la noticia subraya la transparencia de los periodistas que revelan la historia. A este secretismo contribuye la alusión al hecho de que dos periodistas veteranos del diario hayan sido excluidos de las reuniones donde se tomaron las decisiones o la sorpresa con la que los trabajadores recibieron la noticia. Gambit (24 de mayo de 2012) y The Huffington Post (24 de mayo de 2015) también aluden al ocultamiento y la reserva de los directivos de Advance Publications: "[...] Empleados de The Times-Picayune se llevaron un shock ante el anuncio. Todos aquellos con quienes Gambit habló dijeron que se enteraron de la noticia a través del The New York Times. Tuve que averiguarlo por Twitter, dice uno de los periodistas". Excepto Jim Amoss, director del periódico durante mucho tiempo, directivos veteranos del diario en papel como Ashton Phelps, serán reemplazados por altos directivos de Advance que estarán a la cabecera de los nuevos experimentos online. Es el caso de Ricky Mathews, editor de Mobile PressRegister y presidente de Advance en Alabama (Misisipi).

El periódico impreso representa el criterio y la selección periodísticos: “¿Qué es una ciudad importante sin un periódico que capture las mayores noticias en su portada cada día?", escribe Nancy Barnes en Star Tribune (3 de junio de 2012). Dale McFeatters, editorialista del Pittsburgh Post-Gazette (4 de junio de 2012) escribe lo siguiente:

"El periódico tradicional es el único comercio que conozco, y donde él va, yo voy. Mi padre entró en el negocio como copy boy. Una de sus primeras noches en el trabajo, estaba pendiente del teletipo cuando un asunto le llamó la atención. Arrancó el papel y lo llevó al editor de noticias del turno de noche. ¿Es importante?, le preguntó".

Por su parte, Nancy Barnes (Star Tribune, 3 de junio de 2012) vincula la "cualidad" de los lectores con la existencia del diario impreso:

"Son educados, comprometidos, participantes activos en la comunidad. Trabajan duro para permanecer informados. Y la mayoría de ellos todavía demandan un periódico impreso al igual que una serie creciente de productos digitales que nos permiten actualizar constantemente las noticias". 
Los artículos sobre el despido de unos 200 periodistas de The Times-Picayune, un $32 \%$ de la plantilla, así como trabajadores de las otras cabeceras de Alabama pertenecientes a la familia Newhouse, inciden en la antigüedad y excelencia profesional de quienes se encontraban en las primeras filas de la redacción o habían sido galardonados por su buen hacer profesional. The New York Post (13 de junio de 2012) habla de los mayores "baños de sangre" de periódico en años. Estos despidos de profesionales de prestigio refuerzan el posicionamiento del diario impreso y sus periodistas en el lado de los estándares de la buena praxis profesional. Ejemplos de este posicionamiento son la mayoría de las noticia sobre la controvertida decisión que invitó a irse del periódico al reconocido crítico gastronómico Brett Ardenson, debido a la fuerte conexión de Anderson con el robustecimiento de la cultura culinaria de Nueva Orleans tras el huracán Katrina (Julia Moskin NYT Blogs, 12 y 13 de junio de 2012; New York Post, 13 de junio de 2012) y, sobre todo, la decisión de prestigiosos periodistas de dejar la empresa antes de aceptar los cargos que se les ofrecía dentro de la nueva plataforma online (Rick Edmonds, Poynter, 18 de junio de 2012).

En su columna de opinión en The New York Times, David Carr (9 de julio de 2012) tacha de "vergonzoso", "cómico" y "terrible" el escándalo por la publicación en diarios como The Chicago Tribune, The Chicago Sun-Times, The Houston Chronicle y The San Francisco Chronicle de noticias falsas suministras por Journatic, una "factoría" de contenidos "hiper-locales" "de bajo coste" (algunas piezas se escribieron desde Filipinas), propiedad en parte de Tribune Company. Seguidamente, Carr alude al rechazo de ofertas de trabajo en la nueva organización de "noticias digitales de bajo coste" por parte destacados profesionales de The Times-Picayune.

La aceleración de la marcha hacia la tecnología digital, codificada de forma positiva por los directivos de Advance Publications, no recibe el mismo crédito en artículos y blogs. La tradición, la historia y la antigüedad de The Times-Picayune choca con experimentos y tentativas de sitios de noticias en la Red. Advance Publications es criticada por forzar la marcha hacia lo digital: "Todo el mundo sabe que las ediciones impresas van por el camino de la máquina de vapor, pero me pregunto si este cambio ha de producirse con tanta prisa", opina Ken Doctor, un consultor de medios, en un reportaje publicado en The New York Times (25 de mayo de 2012). Campbell Robertson titula así la noticia sobre el despido de periodistas en cuatro periódicos propiedad de Advance Publications (The New York Times Blog, 12 de junio de 2012): "Grandes reducciones de plantillas impuestas a periódicos en Nueva Orleans y Alabama" (la cursiva es mía). El artículo recoge las declaraciones de Jim Amoss, director del periódico donde, una vez más, el sacrificio del prestigio y la antigüedad de algunos periodistas despedidos se justifican "tanto por razones económicas como por la nueva aproximación digital al periodismo". Estas afirmaciones contrastan con las de Charles J. Dean, veterano periodista de política en The Birmingham News: "Es difícil. Esta mañana me notificaron que, simplemente, no encajaba".

Si bien artículos y comentarios en blogs contienen el argumento del colapso económico de la prensa, también recogen datos sobre la resistencia del papel al declive de la industria del periódico. "Aunque el papel desaparece en la era digital, sigue siendo el oxígeno económico de los periódicos", publica el The Washington Post (25 
de mayo de 2012). El periódico ofrece datos que apoyan los ingresos relativamente altos que el papel proporciona a la industria de los periódicos frente a los bajos ingresos procedentes de la Red (Poynter., 18 de junio de 2012).

\section{3. versus individuo}

The Times-Picayune no solo sustenta los valores de la profesión periodística sino que, además, mantiene a la comunidad (de Nueva Orleans). "Nueva Orlans clama por su periódico", titula un artículo de Wall Street de12 de junio de 2012. Es el diario de la ciudad, con el índice de penetración de periódicos regionales más alto de Estados Unidos; la institución comunicativa por excelencia de la sociedad civil en Nueva Orleans. El discurso ciudadano se deja ver en las páginas del periódico: "Una comunidad como Nueva Orleans necesita un diario; aquí es donde comienza el discurso y el diálogo cívico", mantiene Anne Milling, representante de una organización cívica, en un artículo del periodista Cameron McWhirter para The Wall Street Journal (12 de junio de 2012). The Times-Picayune pone de manifiesto la universalidad de un discurso en el que todos tienen voz: "En una ciudad con una docena de acentos distintos, The Picayune es la voz de todos ellos. Un millón de historias. Un millón de narradores", escribe Chris Rose, ex-reportero de The Times Picayune (Oxford American, 27 de agosto de 2012). Y David Carr publica lo siguiente en el blog de The New York Times, "Media Decoder" (5 de junio de 2012):

"Como vehículo de noticias diarias, The Times-Picayune ha representado a la gran comunidad de Nueva Orleans durante más de 175 años, mediante el desempeño de tres funciones cruciales: asegurar el acceso de todos a las noticias, ofrecer una información seria que protege al público y generar una conversación común y una cohesión cultural entre todos los ciudadanos de Nueva Orleans".

El periódico y sus periodistas -algunos de ellos están siendo despedidos- han preservado a la comunidad de la corrupción política mediante exposición y denuncia pública de escándalos políticos: "Durante 175 años, The Times-Picayune ha formado parte del ritmo de la vida de Nueva Orleans, una ciudad hermosa y trágica a la vez, con una historia de corrupción y crimen, pobreza y desastres naturales", escribe el periodista Sean Cockerham en Buffalo News (24 de junio de 2012). Incluso la clase política, criticada y denunciada por The Times-Picayune, reconoce el rol que el diario ha jugado en la consolidación de las instituciones civiles en Nueva Orleans: "La dedicación y profesionalidad de los periodistas han hecho que nuestras instituciones cívicas, empresariales y educativas sean más fuertes, transparentes y honestas", afirma el alcalde de la cuidad, Mitch Landrieu, en un artículo publicado en The Washington Post (27 de mayo de 2012).

El artículo de Cockerham (Buffalo News, 24 de junio de 2012) citado antes recoge los sentimientos de sorpresa, indignación y tristeza de ciudadanos al igual que lo hacen otros medios (Gambit, 13 de junio de 2012; National Journal, 15 de junio de 2012; The New York Times, 5 de junio de 2012), incluido el propio The Times-Picayune (5 junio de 2012). El grado de afectación en la ciudadanía adquiere aquí un tono trascendental, casi místico. Cockerham incluye la opinión del reverendo Donald Jean- 
jacques, pastor protestante de una iglesia situada en un vecindario violento y conflictivo de la ciudad. El reverendo ha instado a su congregación a rezar por The TimesPicayune y los reporteros que están perdiendo sus puestos de trabajo: "[El pastor] calificó al periódico de "tónico" y dijo que muchos en su rebaño serían excluidos por los cambios. Según un informe de Kaiser Family Foundation de 2010 -explica Cockerham- el 36\% de la gente de Nueva Orleans no tiene acceso a Internet en sus casas". Es el mismo tono que emplea The New York Times (25 de mayo de 2012) para referirse a la "íntima relación que tradicionalmente han tenido los 'New Orleanians' con su periódico"; una cercanía que emplaza al diario en el espacio sacro de la sociedad civil. Chris Rose (Oxford American, 27 de agosto de 2012) describe también este vínculo de la ciudad con el periódico en términos de ritual:

"Uno por uno, los manifestantes han lamentado la pérdida de su ritual matutino, que es el tiempo sagrado del despertar y la reflexión, donde leer el periódico es tan vital como el baño y el desayuno. Lo comparten con sus cónyuges. Lo leen de atrás hacia adelante. Hacen los crucigramas; nada de lo cual, han recordado a Mathews, se logra fácilmente en un ordenador".

Inversamente, las acciones de recortes emprendidas por los directivos de Advance Publications les excluyen de esta comunidad, a la vez que les sitúan en el espacio profano de valores anti-cívicos. En concreto, dicha exclusión se pone de manifiesto en noticias y declaraciones publicadas a propósito la oposición y movilización de los ciudadanos. Estas remarcan la procedencia "extranjera" de empresarios y editores que están detrás de los cambios, quienes incluso en algunos casos aparecen simbólicamente caracterizados como enemigos de Nueva Orleans:

La noticia [sobre la reducción de la presencia impresa de The Times-Picayune] se hizo pública el miércoles a altas horas de la noche y el mismo jueves por la mañana algún bromista había pintado un dibujo de un gato gordo en una pared en Bywater en el que imploraba a los políticos locales que "salvaran The T-P de codiciosos editores de fuera de la ciudad" (The New York Times, 28 de mayo de 2012).

Es algo que todos hemos sentido antes", dijo [una de los líderes locales entrevistado por el periodista]. "Es una sensación familiar. Cambian las circunstancias, pero no la reacción de toda la cuidad. En Nueva Orleans, rodeamos a las tropas y pasamos a nuestro modo de defensa, de modo que no permitimos que nadie nos ataque sin estar allí todos juntos. Es una relación muy singular que siempre hemos tenido con esta ciudad aquí.

Usted puede sentir esta relación de todas partes de la ciudad estos días. [Comenta ahora el autor del artículo]. Una vez más, la gente abandonada de Nueva Orleans -esta vez por barones grandes corporaciones norteñas, esta vez, y una vez más, por tipos extranjeros- está cabreada porque, con tan solo una firma, por algunas manos alzadas en una sala de conferencias corporativa, o simplemente por real decreto, alguien, en alguna parte, pueda llevarse su preciado diario (Oxford American, 27 de agosto de 2012).

Las medidas son calificadas de insolidarias. Tracie Powell (Poynter, 5 de julio de 2012) argumenta que el aceleramiento digital no solo convertirá a Nueva Orleans en la primera ciudad más grande de Estados Unidos sin un diario impreso, sino que "sus residentes probablemente se conviertan algunos de los más desconectados del país". Jesse Hardman (Columbia Journalism Review, 28 de junio de 2012) comparte la 
misma opinión: "[dado que solo el $43 \%$ de estadounidenses que ganan menos de 25.000 dólares al año tienen acceso a Internet en casa] está claro que, en medio del cambio a las noticias digitales, mucha gente todavía necesita acceder a la información sin que sea a través de un ordenador". Reportajes, columnas de opinión y blogs critican esta falta de solidaridad cuando interpretan y comentan la carta-manifiesto firmada por el Grupo de Ciudadanos de The Times-Picayune, movilizaciones a favor de los periodistas despedidos o manifestaciones en contra de la decisión de recortar la edición impresa. Un artículo en The New York Post (13 de junio de 2012) intercala extractos de la carta dirigida a la familia Newhouse y firmada por un grupo de "líderes comunitarios": "Advance Publications y sus líderes han perdido la confianza y credibilidad de una parte considerable de la comunidad", reza uno de los comentarios. Frente al "nosotros" que conjuga la carta -"nuestra ciudad", "nuestro diario"-, la familia Newhouse, considerada hasta ahora como amiga de la comunidad, emplea el "yo" del individuo al que se dirigen las páginas web de noticias.

\section{Conclusiones}

No hay nada de particular en las circunstancias económicas que han conducido a los empresarios de Advance Publications a reducir la edición impresa de The Times-Picayune. Internet ha multiplicado los espacios publicitarios y los accesos del público potencial cliente-, a la información. En la era digital, la inversión por publicidad y ventas cae vertiginosamente. Como afirma el periodista David Carr en The New York Times (28 de mayo de 2012), "a excepción de unos pocos días 'gordos' como los viernes o los domingos, [...] muchos periódicos llegan a las casas pareciéndose más bien a delgados folletos que a sus antepasados de peluche". De hecho, representantes de Advance dejan claro las razones económicas que justifican las medidas adoptadas. Hay que salvar al querido y galardonado The Times-Picayune del colapso del negocio del papel. De este modo quedará a salvo lo que le diario ha representado: periodismo de calidad, crítico y de servicio al ciudadano. Principalmente, hay que conseguir que el buen hacer del diario y sus periodistas abanderen la nueva era de innovaciones tecnológicas mediante su reconversión hacia lo digital.

Estos argumentos que justifican los cambios, así como y los discursos periodísticos que los incorporar a las noticias, reportajes y columnas, remiten a un conjunto de códigos culturales presentes ya en otros momentos clave del debate sobre la profesión periodística en Estados Unidos. Es el caso de la revolución del cable de los años ochenta que afectó al periodismo televisivo. Los avances tecnológicos significaron más tiempo para la cobertura informativa, lo cual equivalía a mayor profundización, periodismo serio y profesional, objetividad y sustancialidad de las noticias (Breeze, 2011). Al igual que entonces, el discurso de la revolución digital se construye a partir de estos valores que la innovación tecnológica parece impulsar.

Pero los recortes en The Times-Picayune y quienes los llevan a cabo, en principio codificados en el lado de valores profesionales y cívicos, también simbolizan lo contrario. "The Times-Picayune ha sido siempre un excelente diario con una reacia y anticuada página Web". (The New York Times, 28 de mayo de 2012). Frente a la excelencia del diario impreso, los sitios web de noticias online ponen de manifiesto 
todo lo opuesto a la seriedad, selección y profundidad del periodismo que hasta ahora se ha hecho en The Times-Picayune. Los discursos periodísticos también cifran las medidas de reducciones y despidos de periodistas en códigos anti-cívicos y contravalores profesionales como el sensacionalismo, la espectacularidad o la fabricación y falsificación de informaciones.

Estos códigos binarios de valores, estándares y normas profesionales son así empleados por defensores y detractores de los cambios para construir los discursos a favor y en contra de la revolución informativa de conlleva Internet y el colapso económico del periódico impreso.

En el caso de The Times-Picayune, los discursos en contra de la reconversión destacan los fuertes vínculos del diario con la comunidad de Nueva Orleans, la cercanía del periódico, el carácter ritual, casi místico, de este vínculo, así como la universalidad y el carácter solidario de sus historias. Estos discursos resaltan una serie de códigos no contemplados hasta el momento entre los estándares profesionales que, cercanos a la norma de la objetividad y la transmisión de informaciones, conforman la ideología de la profesión en Estados Unidos (Schudson, 2001; Deleuze, 2005). La fuerte oposición de los ciudadanos de Nueva Orleans -paradójicamente en las nuevas plataformas digitales-, sería ya sintomática de que estamos ante aquellos otros valores que, por encima de este credo profesional, permitirían referir la actividad periodística al bien común de la sociedad civil. The Times-Picayune representa, sin duda, un caso muy singular que habría que testar en otros ejemplos. Antes sería interesante examinar los discursos de los ciudadanos para compararlos con los textos de los periodistas. En cualquier caso, según los artículos ya analizados, no parece que los sitios web de noticias ni el consumo individualizado de informaciones que estos representan suplan, por el momento, el carácter colectivo, de ritual social, que los periodistas otorgan al diario impreso.

\section{Referencias}

ALEXANDER, Jeffrey C. (2006): The Civil Sphere. Nueva York, Oxford University Press.

ALEXANDER, Jeffrey C. (2011): Performative Revolution in Egypt: An Essay in Cultural Power. USA, Bloomsbury Academic.

ALEXANDER, Jeffrey C., JACOBS, Ronald N. (1998): "Mass Communication, Ritual and Civil Society", en LIEBES, Tamar y CURRAN, James (eds.): Media, Ritual and Identity. Londres, Routledge, pp. 23-41.

ALTERMAN, Eric (2011): "Out of Print. The Death and Life of the American Newspapers", en MCCHESNEY, Robert W. y PICKARD, Victor (2011): Will the Last Reporter Please Turn Out the Lights: The Collapse of Journalism and What Can Be Done to Fix It. Nueva York, The New Press.

BREEZE, Elisabeth (2011): "The Binary Structure of American News and the Cable Revolution, 1978-1983”, comunicación presentada en el 2012 Yale CCS Congreso Internacional, Yale University, New Haven, 29 y 30 de abril. 
CAREY, James (1992): Communication as Culture. Essays on Media and Society. Nueva York, Londres, Routledge.

CARLSON, Matt (2012): "Rethinking Journalism Authority", Journalism Studies, vol. $13, n^{\circ} 4$, pp.483-498.

CARR, David (2012): “A doomed romance with a paper”, The New York Times, 28 de mayo.

CARR, Sarah (2012): "How to worry about a clicks-driven Times-Picayune", Columbia Journalism Review, 20 de julio de 2012.

DAYAN, Daniel, KATZ, Elihu (1992): Media Events: The Life Broadcasting of History. Harvard: Harvard University Press.

DELEUZE, Marc (2005): "What is Journalism? Professional identity and ideology of journalists reconsidered”, Journalism, vol. 6, n. 4, pp. 442-464.

EDMONDS, Rick (2012): "Cutting print is a money-loser for Times-Picayune, but cutting staff changes slightly profitable", Pointer.com, 18 de junio.

FARIAS, Pedro y ROSES, Sergio (2009): "La crisis acelera el cambio del negocio informativo". Estudios sobre el Mensaje Periodístico, vol. 15, pp. 15-32. Madrid, Servicio de Publicaciones de la Universidad Complutense.

FULLER, Jack (2010): What is Happening to the News: The Information Explosion and the Crisis in Journalism. Chicago, The University of Chicago Press.

JACOBS, Ronald N. (2000): Race, Media and the Crisis of Civil Society: From Watts to Rodney King. Cambridge, Cambridge University Press.

JACOBS, Ronald N. (2009): "Culture, the Public Sphere, and Media Sociology: A Search for a Classical Founder in the Work of Robert Park". The American Sociologist, vol. 40, $\mathrm{n}^{\circ} 3$, pp. 149-166.

JONES, Alex S. (2009): Losing the News: The Future of the News That Feeds Democracy. Oxford, Oxford University Press.

LARRAÑAGA, Julio (2009): "La crisis del modelo económico de la industria de los periódicos”, Estudios sobre el Mensaje Periodístico, vol. 15, pp. 61-80. Madrid, Servicio de Publicaciones de la Universidad Complutense.

MCCHESNEY, Robert W. y PICKARD, Victor (2011): Will the Last Reporter Please Turn Out the Lights: The Collapse of Journalism and What Can Be Done to Fix It. Nueva York, The New Press.

MYERS, Steve (2012): "Will New Orleanians follow The Times-Picayune online after it cuts back on print?", Poynter.com, 25 de mayo.

PATTERSON, Thomas E. and DONSBACH, Wolfgang (1996): "News Decisions: Journalists as Partisan Actors", Political Communication, n. 13, pp. 455-468.

PÉREZ-LATRE, Francisco y SÁNCHEZ-TABERNERO, Alfonso (2012): La ruta del cambio. Pamplona, EUNSA. 
REVERS, Matthias (2012): "Journalistic Autonomy as Cultural Practice: Boundary Work and Performance in Political News Production", comunicación presentada en el 62nd Annual ICA Conference, Phoenix, AZ, USA, 24-28 de mayo.

SCHUDSON, Michael (1978): Discovering the News: A Social History of American Newspapers. New York, Basic Books.

SCHUDSON, Michael (2001): "The objectivity norm in American journalism”, Journalism, v. 2 , n. 2 pp. 149-170.

SOFFER, Oren (2009): "The Competing Ideals of Objectivity and Dialogue in American Journalism", Journalism, vol. 10, num. 4, pp. 473-491.

STATHAM, Paul (2008): "Making Europe News: How Journalists View their Role and Media Performance". Journalism, vol. 9, n 4, pp. 398-422.

STEARNS, Josh (2012): "Deep cuts at the New Orleans Times-Picayune Trigger thoughts about journalism's future", Freepress.net, 24 de mayo.

STRAUSS, Anselm, CORBIN, Juliet (1998): Basic of Qualitative Research. Londres, SAGE.

WEILL, Georges (1941): El diario. Historia y función de la prensa periódica. México, Fondo de Cultura Económica.

VV.AA. (2009): El fin de los periódicos. Barcelona, Duomo Ediciones 